\title{
TENSÕES ENTRE ESFERAS DE GOVERNO NA EDUCAÇÃO A DISTÂNCIA: A LEGISLAÇÃO FEDERAL E A GESTÃO DA UNITINS
}

http://dx.doi.org/10.5902/2176217110572

\author{
Daniel Perdigão Nass \\ Universidade Federal do Tocantins, Brasil.
}

Resumo

Neste trabalho buscou-se explorar aspectos da gestão dos cursos superiores na modalidade a distância - EAD - da Fundação Universidade do Tocantins - Unitins - e sua interação com os entes legislativos e administrativos federais da área. Para isto, realizou-se um levantamento de documentos que descrevessem práticas pedagógicas, gerenciais e administrativas internas. A análise se baseou em referenciais da área da EAD e da gestão democrática da educação. Concluiu-se que vigorou a lógica de mercado na gestão da EAD na Unitins, com a priorização de lucros e rendas em detrimento dos índices de qualidade, mas que os entes federais tiveram um papel crescentemente ativo na gestão universitária, buscando garantir uma solução adequada no processo que culminou no descredenciamento da instituição.

Palavras-chave: educação a distância, políticas educacionais, gestão democrática.

\section{STRESSES BETWEEN LEVELS OF GOVERNMENT IN DISTANCE EDUCATION: FEDERAL LAW AND THE MANAGEMENT OF TOCANTINS STATE UNIVERSITY}

\begin{abstract}
This research aimed to explore management aspects of higher distance education in Unitins, focusing the university interaction with federal laws, rules and government agents. The research was performed using documents that describe teaching and management practices of Unitins. The analysis was based on benchmarks of distance education and democratic management in education. The conclusions indicate that priority to profits and economic benefits prevailed in the management of distance education in Unitins; hence, educational quality was not safeguarded in Unitins. On the other hand, federal agents had an increasingly active role in Unitins management by coordinating efforts to ensure an adequate solution for the disaccreditation of the institution.

Key-words: distance education, education policy, democratic management style.
\end{abstract}




\section{Introdução}

o Brasil, em todos os níveis de governo e, também, na iniciativa privada, observa-se um investimento crescente em educação superior na modalidade a distância. Os programas de educação a distância - EAD - estão na pauta da agenda governamental. Desde o início da década passada, a legislação da área vem sendo intensamente revista e ampliada, e a produção científica sobre o assunto é cada vez maior. Novos cursos são criados, com formatos convencionais ou inovadores.

Mesmo com a consolidação da modalidade, ainda persistem dúvidas e preconceitos. A discussão da EAD como uma política pública de inclusão e de desenvolvimento social e econômico envolve interesses diversos. As críticas que a modalidade EAD recebe de muitos especialistas em educação são pesadas e, no mínimo, devem ser discutidas e examinadas, uma vez que os cursos superiores nesta modalidade já estão legalmente autorizados e implantados. Isto passa, obrigatoriamente, por compreender aspectos da política, da legislação e da gestão educacional que rege a EAD em nível superior no Brasil, bem como os entendimentos e desentendimentos entre os diversos agentes públicos e a iniciativa privada, as eventuais mudanças de gestão e políticas educacionais, os objetivos e as características peculiares da gestão da educação na modalidade a distância, entre muitos outros fatores.

Neste contexto, o caso do Estado do Tocantins é especial. Trata-se do último Estado a ter a sua própria universidade federal, instalada apenas em 2003 e originada de parte da estrutura física, dos recursos humanos e do alunado da Fundação Universidade do Tocantins - Unitins -, instituição estadual que teve alguns de seus campi universitários federalizados ao longo de um processo que descreveremos mais adiante. A Unitins, depois de perder seus campi, decidiu investir em EAD paga, sendo a primeira, entre as instituições públicas brasileiras de ensino superior, a oferecer vasta gama de graduações na modalidade, não só no Tocantins, mas em todos os Estados brasileiros.

A partir de um levantamento bibliográfico preliminar, pudemos constatar a relevância desta categoria de trabalho acadêmico na área de Gestão Educacional, embora haja poucos registros de trabalhos nacionais dedicados à análise da gestão de cursos superiores a distância, contrastando com o grande volume de análises de cursos presenciais ou de análises de aspectos pedagógicos de cursos EAD. A relevância deste tipo de pesquisa reside na importância crescente da educação a distância como modalidade educacional, tanto em instituições públicas quanto privadas. Neste campo, o caso Unitins é especial, uma vez que, ao longo da década de 2000 , esta instituição estadual foi uma das universidades brasileiras com maior número de alunos em todo o território nacional.

Justifica-se, assim, nosso trabalho, tendo em vista sua reflexão teórica e metodológica sobre os limites e as precariedades da gestão e das políticas públicas de um sistema de educação a distância. Buscamos aprofundar os aspectos teóricos e práticos que alicerçam a gestão de EAD, especialmente no que tange à legislação e regulação, visando à contribuição crítica quanto às características desta gestão.

O objetivo principal desta pesquisa foi o de explorar e compreender, a partir da análise crítica dos dados obtidos, aspectos da gestão da educação superior na modalidade EAD na Unitins no que tange à interação com os entes legislativos e administrativos federais da área. O que procuramos investigar com mais atenção neste 
estudo foi a relação entre os entes federal, que regula e fiscaliza a educação a distância no país, e estadual, que detém a gestão da universidade aqui retratada.

São diversos os fatores que podem vir a influenciar, de forma positiva ou negativa, a relação entre os entes públicos das diversas esferas de governo. Eliasquevici e Prado Jr. (2008) trazem um panorama das principais resistências à implantação de EAD. Algumas destas oposições correspondem à esfera das políticas públicas; outras correspondem às tensões entre o público e o privado. Certos questionamentos colocados pelos referidos autores nos serviram de baliza para a elaboração das nossas questões de pesquisa, por virem à tona ao longo do processo de implementação de sistemas de EAD. Adaptamos alguns deles para responder particularmente para o caso da Unitins:

1) Dentre os fatores políticos que colocam em risco a implantação de projetos e sistemas de EAD, quais influenciaram o caso Unitins? De que forma isto aconteceu?

2) Que papel desempenharam os agentes governamentais federais e estaduais no caso Unitins?

3) Como interagiram os interesses dos agentes públicos e privados no que tange à estruturação e gestão da EAD na Unitins?

Com estes objetivos específicos, buscamos discutir de que forma estes desencontros influenciam a postura de um nível de governo em sua relação com outro, esperando ter trazido novos elementos que permitam a ampliação dos instrumentos e aspectos de controle ou a implantação de novas políticas públicas que assegurem qualidade na gestão da $E A D$, bem como na própria educação oferecida nesta modalidade, enriquecendo, assim, a experiência teórica de gestão das políticas públicas da modalidade EAD no contexto nacional.

\section{Metodologias de pesquisa}

Buscamos responder às questões de pesquisa fazendo um levantamento de documentos oficiais, de jornais e de revistas de circulação pública, bem como de teses e dissertações de professores e ex-professores da Unitins, nas quais certas práticas pedagógicas, gerenciais e administrativas internas foram descritas, em busca de informações sobre as iniciativas políticas e sociais que levaram às decisões efetivamente tomadas. Artigos científicos e documentos acadêmicos da área de Educação e de Gestão Educacional também nos serviram de fontes, além da legislação da área e da regulamentação dos projetos.

A partir destas fontes consultadas, buscamos, no que tange à legislação da educação a distância no Brasil, todas as alterações legais que influenciaram a postura das universidades na implantação e no desenvolvimento de seus cursos na modalidade. Em especial, focamos os dispositivos legais que mais influenciam a gestão dos cursos, como os que determinam referenciais de qualidade, autorizações de funcionamento e aspectos pedagógicos, estruturais e de fiscalização.

Quanto à regulação da EAD e, em especial, do processo de fiscalização da Unitins pela Secretaria de Educação a Distância do MEC, demos ênfase na busca por informações prestadas pelos professores da Unitins em suas dissertações e teses, bem como em documentos oficiais gerados ao longo do processo de descredenciamento da Unitins, com atenção às diferenças na visão de cada agente sobre o mesmo evento. 
Utilizamos, também, dados sobre a história da Unitins e as mudanças na sua constituição, bem como estatísticas sobre a expansão da modalidade a distância no Brasil e na Unitins.

A análise e a interpretação dos dados levantados e produzidos foram feitas à luz do conhecimento dos autores e das metodologias aqui explicitadas, com base nos referenciais teóricos que serão abordados no capítulo a seguir, sendo eles da área da educação a distância, bem como da área da gestão democrática.

A partir deste levantamento, pudemos historiar o processo de implantação, desenvolvimento e ocaso dos cursos não gratuitos a distância oferecidos pela Unitins. Tomando como ponto inicial este levantamento da história e da legislação federal da área, que foi se modificando ao longo dos anos 2000 , bem como de processos de avaliação levados a cabo pela Seed-MEC junto à Unitins, pudemos correlacionar as decisões federais e estaduais no período.

Ainda que se trate de um estudo de caso, fornecemos caminhos teóricos e práticos para o aperfeiçoamento dos programas, projetos e sistemas educacionais no que tange à gestão da educação superior a distância. Mais especificamente, olhamos para um caso do Estado do Tocantins; contudo, não nos limitamos a buscar conclusões válidas apenas para este Estado, mas que permitirão um olhar sobre questões que envolvem a gestão da EAD em plano nacional.

\section{A educação a distância}

Moraes (2010) introduz o tema da EAD de forma contundente. Para o autor, se afirmar que a educação representa o único caminho para a salvação do mundo permitir, por extensão, dizer que todos os problemas do mundo se devem às falhas da educação, sendo a EAD uma modalidade de educação, poderíamos nos ver livres para endeusar ou satanizar a EAD, conforme nossas convicções pessoais. Além disso, para o autor, a EAD é fator de desenvolvimento da educação como um todo, seja da educação presencial ou da não presencial, por se colocar, desde o princípio, no campo do novo, da transgressão, do desafio, do direito à tentativa e ao erro, da permissão para ousar no desenvolvimento de métodos e materiais.

A EAD teria se desenvolvido induzida pela existência de uma demanda criada por pessoas, localidades ou grupos sociais em confinamento ou em isolamento físico ou temporal. Ou seja, indivíduos teriam a necessidade de estudar, mas a impossibilidade de espaço (pela distância ou pela dificuldade de deslocamento) ou de tempo (falta de flexibilidade de agenda, impossibilidade de presença em dois lugares simultaneamente) teria os impedido de usufruir do ensino presencial (Moraes, 2010).

Apesar desta demanda crescente, este recente desenvolvimento da EAD só foi possível porque houve o desenvolvimento das tecnologias de informação e comunicação (TIC), com consequente redução de custos. Mas a EAD já existia antes das TIC; logo, devemos evitar reduzir a EAD à ideia de um ensino mediado por tecnologias. $O$ conceito de EAD englobaria maneiras diversas de organização do ensino e aprendizagem, incluindo a estimulação e o apoio à autoinstrução e ao estudo independente, mas não somente. Tal conceito também deve incluir a regulamentação do setor, afinal, segundo o autor, o sistema escolar também opera na EAD validando e certificando publicamente a aprendizagem dos seus alunos. 
Para Preti (1998), há um aspecto a ser levado em consideração no uso de novas tecnologias na EAD: a tentação de buscar acompanhar as mudanças, sempre muito velozes, nas TIC. Para o autor, trata-se de um risco, pois estudos teriam apontado que uma tecnologia introduzida em cursos de EAD exige manutenção por, pelo menos, cinco anos para ser eficaz. Ou seja, é necessária tecnologia estável, para que os atores do processo educacional possam conhecê-la, desenvolvê-la, testá-la e avaliá-la melhor. Há razões, portanto, para imaginarmos que a gestão da EAD também siga a tendência de necessidade de manutenção das políticas por prazos longos, por razões assemelhadas: alunos distantes têm representatividade limitada nos órgãos decisórios da universidade e não se engajam na política universitária, como acontece no ensino presencial com os diretórios acadêmicos.

Por estas e outras razões, Dourado (2008) questiona, por um lado, a adesão acrítica à implementação da modalidade EAD, quando entendida como solução dos problemas relativos à formação universitária em um país vasto como o nosso, assim como questiona posições totalmente refratárias a EAD, de quem só vê, nessa modalidade, forma de acelerar formação inicial e continuada. Para este autor, a centralidade na discussão sobre a modalidade, ou seja, sobre a presencialidade ou a distância, tira o foco do essencial, como o projeto pedagógico, as condições objetivas de ensino-aprendizagem, a gestão e as políticas públicas, entre outros fatores, sendo fundamental romper com o conceito de que a existência e o uso da tecnologia são diretamente responsáveis pela qualidade do processo educativo.

De forma mais intensa nos últimos 15 anos, observa-se, como fenômeno mundial, uma expansão da modalidade a distância no ensino superior. Esta expansão se dá de variadas formas institucionais (Moraes, 2010; Preti, 1998). Há, segundo Bates (2000), dois modelos principais de instituição a ofertar educação a distância: as de modo único, ou seja, instituições que ofertam apenas cursos a distância, tendo sido fundadas para este fim ou tendo se convertido em uma destas instituições (como no caso Unitins, mais raro no Brasil); e as de modo duplo, instituições que ofertam cursos presenciais e a distância.

Barreto (2004) faz uma distinção entre as propostas de uso das TIC na educação superior nos países em desenvolvimento, em relação ao seu uso nos países desenvolvidos. Para a autora, nos países desenvolvidos, o uso de TIC pretende agregar novas possibilidades aos processos pedagógicos, enquanto nos países como Brasil, Uganda e Vietnã, tal uso configura estratégia de substituição tecnológica, relacionando-se à certificação em massa, sem preocupação com o aspecto do aprendizado. Gouvêa e Oliveira (2006) complementam tal discurso, entendendo que a EAD parece ter, no Brasil, caráter de modalidade alternativa, secundária, especialmente determinada pelos entes públicos, entendida como modalidade de ensino a serviço de uma compensação de uma defasagem na formação do trabalhador ou, mais especificamente, do professor.

A história da educação superior brasileira a distância inicia-se na década de 1980, com a criação dos primeiros cursos de extensão a distância na Universidade de Brasília (UnB). No âmbito do Ministério da Educação, as principais ações para a implementação da EAD também se dirigiam à instalação de cursos de nível superior. Entre elas, está a TV Escola, programa criado em 1995 para o aperfeiçoamento e a valorização dos professores e gestores da rede pública de educação básica (GOUVÊA; OLIVEIRA, 2006). 
Em 1998, houve a criação da Universidade Virtual do Centro-Oeste, com sede na UnB. Esta iniciativa foi como um embrião da Universidade Virtual Pública do Brasil (UniRede), uma das duas iniciativas pioneiras para a oferta de cursos de graduação a distância no Brasil. A outra iniciativa foi o Consórcio de Educação Superior a Distância do Estado do Rio de Janeiro (Cederj) (Gouvêa; Oliveira, 2006). É neste contexto que a Unitins começa a planejar a abertura de seus primeiros cursos a distância, como veremos.

\section{Gestão democrática e educação superior a distância no Brasil}

Em relação ao contexto político que baseou a expansão da educação superior a distância no Brasil, é preciso notar o projeto de modificação da organização e de reordenação da gestão e da política educacional em busca de descentralização, de municipalização, de participação comunitária e de gestão democrática e modernizada determinados pela Constituição Federal de 1988, nos incisos VI e VII do seu artigo 206. A ideia dos constituintes era a de assegurar a equidade e a qualidade do ensino, ao mesmo tempo em que se garantiria um incremento da cidadania e da ordem democrática (FREITAS, 1998).

Em fins da década de 1990 e no início da década de 2000, o modelo de gestão educacional federal passa a buscar a redução da atuação do Estado como provedor do serviço educacional, procurando viabilizar formas de oferecimento da educação por meio de agentes não governamentais e aumentar a eficiência do Estado nos processos que permaneciam sob sua responsabilidade executiva direta. Esta política, que permeava toda a ação do Estado na esfera social, tinha como princípios a focalização, a flexibilização e a mobilização (Freitas, 1998). Souza (2007) identifica que este posicionamento coincide com o período de existência do Ministério da Administração Federal e de Reforma do Estado, entre 1995 e 1998. Esta autora ainda acrescenta que os princípios que regem a reforma educacional da época priorizam políticas de flexibilização, de diferenciação institucional e de avaliação, de acordo com um ideário dito neoliberal.

Silva Jr. (2003) cita autores que entendem que, sob este ideário, na relação dicotômica entre professores e tecnologia educativa, a opção sempre se faz pela tecnologia, no sentido de buscar um substituto para o professor, ou seja, busca-se uma "solução" para seus baixos salários, sua formação deficiente e outros problemas, e não um apoio à função docente. Para o autor, esta ausência de preocupação com a formação do educador voltada para a elevação da condição humana não deve ser pensada como um fato de um único país; tratar-se-ia de um movimento mundial, com especificidades, mas com uma identidade comum.

Note-se que foi exatamente na mesma época, em 1996, que a EAD como modalidade de ensino se estabeleceu como parte do sistema de educação formal brasileira, ao ser incluída como alternativa de diversificação do sistema de ensino, conforme o artigo 80 da lei 9394/96, conhecida como Lei de Diretrizes e Bases da Educação Nacional. A questão que se coloca é a de tentar identificar se a priorização da EAD em nível público federal pretendia ser, meramente, uma forma de simular uma democratização do ensino, apenas reduzindo custos, ou se foi idealizada para, de fato, ampliar o acesso de qualquer brasileiro à educação. 
Sabe-se que a decisão de projetar e implementar qualquer sistema de EAD, seja público ou privado, é, também, uma decisão política, uma decisão de gestão política. No entanto, ainda que, aparentemente, existam o desejo e a vontade política, as instalações físicas, a disponibilidade para a contratação de profissionais, entre outros elementos importantes, a sua mera existência não é suficiente. Para Eliasquevici e Prado Jr. (2008), é necessário, também, haver sintonia entre os fatores que são indispensáveis e os que estão disponíveis e, para isso, é preciso conhecer a realidade na qual o processo está inserido e suas limitações. Assim, só seria possível avançar se houvesse políticas claras, traduzidas em planos e programas viáveis, com pleno conhecimento de todos os fatores e demais agentes envolvidos. Portanto, o sucesso de projetos de EAD seria dependente do bom planejamento e da boa administração do processo.

Os mesmos autores acreditam haver cinco objetivos e motivações que levariam instituições e governos a investir em EAD: a) democratizar o acesso à educação; b) possibilitar uma aprendizagem autônoma e ligada à experiência; c) investir em um ensino inovador e com qualidade; d) fomentar a educação permanente; e e) reduzir o custo per capita com educação (Eliasquevici; Prado Jr., 2008). Entendemos que tais motivações descrevam adequadamente sistemas em que os níveis de governo ofereçam ensino gratuito. Na possibilidade de oferecerem educação superior paga, um sexto objetivo ou motivação impulsiona o investimento em educação: f) a possibilidade de obter lucro ou superávit nas contas públicas. Por conta destas vantagens, todas interessantes ao gestor público, seja do ponto de vista político ou do administrativo, observa-se, ao longo da década de 2000, um significativo aumento da oferta de cursos, como se a EAD fosse de implementação simples.

Para Alonso (2010),

é possível afirmar que há uma lógica na expansão do ensino superior brasileiro, claramente privatista, quantitativista e concentrada em determinadas áreas do conhecimento. A EAD não estaria, obviamente, alheia a esse fenômeno. Isto é importante para verificarmos que a contradição expansão versus qualidade da educação superior brasileira não se restringe apenas à modalidade em que se dá a oferta dos cursos. É possível evidenciar certa aceleração dessa expansão no caso da EAD, considerando as variáveis tempo e número de alunos. Isto, contudo, não interfere na lógica antes referida (p.1324-1325)

O Plano Nacional de Educação da década 2001-2010, aprovado pela lei 10172, de 9 de janeiro de 2001, tratava abertamente da educação superior a distância no Brasil. Uma das metas, inclusive, era a de estabelecer um "amplo sistema interativo de educação a distância, utilizando-o, inclusive, para ampliar as possibilidades de atendimento nos cursos presenciais, regulares ou de educação continuada", prevendo, também e em curto prazo, a constituição de um projeto de universidade aberta. A palavra "distância" aparece 37 vezes nesse documento.

Assim, questionar se a EAD atende a uma demanda social ou a uma demanda comercial não leva a uma única resposta, havendo posições antagônicas entre os autores consultados, bem como autores que não colocam tal questionamento como pertinente. De qualquer forma, a partir desta discussão referencial levada a cabo até este ponto, podemos começar a estudar o caso Unitins. 


\section{A legislação federal de educação a distância}

A Secretaria de Educação a Distância (Seed) foi criada, no âmbito do Ministério da Educação (MEC), pelo decreto n. 1.917, de 27 de maio de 1996, incorporando a Subsecretaria de Educação a Distância, implantada no âmbito da Secretaria de Comunicação da Presidência da República, em 1995. Também em 1996, a lei n. 9.394, de 20 de dezembro, trouxe no artigo 80, a extensão do alcance da EAD, ou seja, à educação a distância estaria permitida para oferecimento em todos os níveis e modalidades de ensino.

O já revogado decreto n. 2.494, de 10 de fevereiro de 1998, pouco tempo depois, ao regulamentar a LDB, restringiu a EAD no nível básico à formação de jovens e adultos. Houve, portanto, afinidade entre o decreto e as políticas de EAD da Seed-MEC, que vinha aparelhando as escolas e operando um suporte a distância aos professores presenciais, mas não fazendo uso direto da EAD na oferta de cursos para o ensino básico.

Para Giolo (2008), até 2003, a EAD no Brasil ainda não teria uma razão de existir suficientemente explícita, havendo uma tendência de seguir exemplos internacionais. Daí, para esse autor, pode ter nascido a busca para dotar o Brasil de uma megauniversidade a distância, nos moldes de instituições como a britânica Open University, entre outras. Silva Jr. (2003) também discute a posição da Seed à época, evidenciando que tal secretaria buscava a estruturação centralizada de um campo de formação de professores, embora, aparentemente, as secretarias estaduais e municipais, bem como as escolas, pudessem usufruir de autonomia. No caso da educação superior privada, Giolo (2010) indica que ela começou a ofertar as primeiras vagas em 2002, representando, nesse ano, 15,7\% de todas as matrículas de EAD superior brasileiras.

Em 2004, com a publicação do decreto 5159, de 28 de julho, definiu-se nova estrutura regimental para o MEC e alterou-se a estrutura da Seed, buscando aumentar o alcance e a eficácia das ações e dos recursos existentes. Entre as competências da Seed definidas em anexo do referido decreto, e aprimoradas no decreto n. 6.320, de 20 de dezembro de 2007, estão "formular, propor, planejar, avaliar e supervisionar políticas e programas de $E A D$, visando à universalização e democratização do acesso à informação, ao conhecimento e à educação e, também, à melhoria do padrão de qualidade da EAD". Nesta época, já se percebia uma expansão extremamente rápida e pouco regulamentada da EAD nas universidades particulares. Afinal, no fim de 2004, as matrículas de EAD pagas na educação superior já representavam $39,6 \%$ da oferta total (Giolo, 2010).

A portaria MEC n. 2.253, de 18 de outubro de 2001, criou a possibilidade de que até $20 \%$ da carga horária total dos cursos superiores presenciais fosse ministrada por ferramentas de EAD. No entanto, apenas após a regulamentação deste dispositivo, por meio da portaria MEC n. 4.059, de 10 de dezembro de 2004, o incentivo que se pretendeu dar em 2001 realmente levou a mudanças significativas no panorama da educação superior presencial, o que, por consequência, também incentivou a criação de cursos totalmente ministrados a distância. Afinal, a redução de custos que a EAD representa só é sentida quando ofertada em grande escala.

Nas instituições federais de ensino superior, o incentivo para a criação de cursos a distância foi dado pela portaria MEC n. 873, de 7 de abril de 2006. Esta portaria autorizava a criação de tais cursos em caráter experimental, e dava dois anos de autorização, antes do credenciamento definitivo. Esta portaria do MEC representa, de 
certa forma, uma preocupação com a expansão desenfreada da EAD. A particular Universidade Paulista, por exemplo, recebeu, em 9 de novembro de 2004, pela portaria MEC n. 3.633, autorização para abrir cursos a distância por 5 anos, e não apenas dois, como as universidades públicas.

O Ministério da Educação mostra outras preocupações com os problemas da EAD, ao promover uma série de medidas regulamentadoras, como os decretos n. 5.622, de 19 de dezembro de 2005; 5.773, de 9 de maio de 2006; 6.303, de 12 de dezembro de 2007 (que altera os dois anteriores), e a portaria normativa n. 40, de 12 de dezembro de 2007, empreendendo um sistema de avaliação que pretendia corrigir as fragilidades detectadas nessa curta trajetória (Giolo, 2008).

O decreto n. 5.622 mencionado acima é frequentemente citado por quem deseja caracterizar a visão do Estado brasileiro sobre o que é educação a distância. Seu artigo $1^{\circ}$ caracteriza a EAD como modalidade vinculada à utilização das TIC na mediação didático-pedagógica. Outro destaque é o parágrafo $1^{\circ}$ do artigo $3^{\circ}$, que diz que os cursos em EAD brasileiros devem ser projetados para ter a mesma duração de seus congêneres presenciais. O mesmo decreto determina que avaliações, estágios, práticas de laboratório e defesas de monografias sejam presenciais. Impõe, também, a existência de polos de apoio presencial, os quais devem ser fiscalizados e só podem ser constituídos com autorização federal.

O decreto n. 5.773 determina quais instituições, secretarias ou autarquias federais têm o papel de fiscalizar ou de regular cada parte da educação superior brasileira a distância. Assim, podemos dizer que o início da observação mais cuidadosa das instituições e de suas ofertas em EAD se deu em 2006, ano em que as matrículas em cursos pagos de EAD já constituíam $81,5 \%$ do total de alunos.

Por fim, o decreto n. 6.303 restringe ainda mais a possibilidade de constituição de locais de atividades presenciais não fiscalizadas, ou seja, polos fantasmas, que existem na prática, mas não estão registrados no MEC. $O$ decreto também veda a constituição de polos fora do Estado de origem da instituição sem a devida autorização federal. Esta decisão sinaliza uma preocupação com a expansão desenfreada.

Esta grande regulamentação da EAD brasileira mostra que ela não é tão aberta, ou seja, tão flexível, em termos das exigências para ingresso, das disciplinas obrigatórias e do tempo para formação quanto a EAD em outros países. Em outros projetos de universidades abertas, está muito presente o conceito da educação centrada no aluno, na formação continuada e contínua e na liberdade curricular. Assim, é preciso destacar que educação a distância não é sinônimo de educação aberta. O caso brasileiro é bem ilustrativo, a despeito de utilizar-se a palavra "aberta" no nome do programa Universidade Aberta do Brasil (UAB), por exemplo.

Giolo (2010) afirma que

a UAB é uma forma essencialmente pública de operar educação a distância, seguindo os caminhos normais das instituições públicas, ou seja, financiada pelos recursos do Estado e oferecida gratuitamente à população. Não toma atalhos. Além de coordenar e conferir organicidade às ações de EAD das instituições federais de educação, deverá servir de parâmetro para as demais instituições oficiais que atuam ou pretendem atuar com educação a distância." (p. 1285) 
Ou seja, para Giolo (2010), a própria existência de um sistema funcional de EAD pública já deveria servir como uma regulamentação implícita. De certa forma, como veremos, a experiência da UAB em termos de relação aluno por tutor, aluno por professor, estruturação mínima de polo, entre outros parâmetros de qualidade, serviram para balizar a avaliação da Unitins, já que os Referenciais de Qualidade para Educação Superior a Distância (Brasil, 2007), ainda que forneçam parâmetros, não trazem números.

O mesmo autor busca mostrar, no mesmo artigo, que a iniciativa privada e seus interesses nunca foram meros espectadores das mudanças nas políticas e na legislação educacional. Giolo (2010) cita a criação da Associação Brasileira de Educação a Distância (Abed) como exemplo de exercício da influência política sob a rubrica de sociedade científica. Ele remete a uma obra escrita pelo presidente e pelo vice-presidente da Abed, chamada Educação a distância: o estado da arte, publicada em 2009, na qual se encontra um texto de autoria do professor da Faculdade de Educação da Universidade de Brasília, Bernardo Kipnis. Um excerto do referido texto diz:

Especificamente para o Brasil, com tradição europeia na educação
superior e colonização patrimonialista portuguesa, a tendência para
centralização do controle e a necessidade do estabelecimento de uma
legislação detalhista a ser seguida impõe uma camisa de força,
principalmente às iniciativas inovadoras. No caso da EAD, apesar dos
avanços conquistados, corre-se o risco de paralisação de um processo
cuja dinâmica, principalmente tecnológica, requer a máxima flexibilidade
possível, deixando para os indivíduos julgarem os resultados alcançados, e
uma legislação apenas direcionadora, com princípios mais gerais. (Kipnis,
2009 , p. 212)

Ainda que já tenhamos tratado do caráter transgressor da EAD, a posição de Kipnis é bastante questionável. Afinal, como veremos a partir de agora, a crescente regulamentação federal da EAD foi insuficiente para garantir, por si só, a qualidade da educação no caso da Unitins.

\section{$O$ caso Unitins}

A Unitins tem origem na Universidade do Tocantins, criada em 1990 como uma fundação estadual de direito público, na esteira da instalação do poder na mais nova unidade da federação. Já em 1992, a universidade passa a ser considerada uma autarquia do governo estadual, incorporando as duas faculdades estaduais instaladas no antigo norte goiano, nas cidades de Araguaína e Porto Nacional (Souza, 2007; Pretto; Pereira, 2008).

Pretendeu-se, no início da história da Unitins, que a universidade se mantivesse isolada das influências político-partidárias existentes no Estado do Tocantins. Uma das ideias era a de constituir um Conselho Comunitário a partir de lideranças locais com poder de deliberação sobre a estrutura superior da instituição, sobre a criação de cursos e, até mesmo, sobre a escolha do titular da reitoria, o que seria uma inovação para o ensino superior das regiões do Centro-Oeste e Norte do Brasil. No entanto, esta intenção nunca se concretizou: pouco tempo depois, já a partir de 1992, tornaram-se rotineiras negociações políticas para a criação de cursos e campi universitários (Pretto; Pereira, 2008). 
Em 1996, a universidade foi administrativamente extinta, e seu patrimônio foi absorvido pela Fundação Universidade do Tocantins, constituindo-se, desde então, como uma fundação de direito privado. Nesse momento, a universidade transformava-se numa instituição pública, mas não estatal de direito privado, mas não particular, de acordo com o texto da lei estadual n. 872/96, de 13 de novembro de 1996. Assim sendo, por regra, a Unitins passou a cobrar mensalidades de seus alunos, permitindo que eventuais alunos que se considerassem carentes solicitassem redução parcial ou total das mensalidades. $A$ própria universidade teria sido posta à venda em anúncio do governo estadual no jornal Correio Braziliense de 18 de março de 2000 (Souza, 2007; Pretto; Pereira, 2008).

Até então, a trajetória da Unitins "é a expressão de uma concepção patrimonial de Estado cuja descontinuidade é um traço marcante e que as decisões não se efetivam em critérios estritamente acadêmicos", Moretz-Sohn (2002, p. 45). Esta autora ainda aponta exemplos de situações a que a Unitins foi submetida: sucessivas mudanças de personalidade jurídica, rotatividade das reitorias, fechamento e abertura de cursos e campi, diversidade de vínculos empregatícios, entre outras intervenções.

A insatisfação da comunidade universitária era crescente e culminou, em 2000, no movimento SOS Unitins, encabeçado pelos estudantes, que resultou na reestruturação do ensino superior do Estado e, conforme determinava a lei estadual n. 1.160/00, de 19 de junho de 2000, na isenção de contrapartidas financeiras. Naquele mesmo ano, foi criada por lei federal a Universidade Federal do Tocantins - UFT -, que absorveu parte do patrimônio da Unitins e de seu alunado de cursos presenciais apenas em 2003 (Pretto; Pereira, 2008).

No mesmo ano de 2000, a Unitins iniciou uma reestruturação, visando a se preparar para a perda dos cursos para a UFT. A estratégia foi a de promover cursos de graduação e de pós-graduação lato sensu a distância na modalidade telepresencial, ou seja, com salas de aula providas de televisores que transmitiam as aulas por satélite diretamente da sede da instituição, na capital Palmas. Para isto, a Unitins firmou contrato particular de prestação de serviços educacionais e de cooperação técnica com a Sociedade Civil de Educação Continuada Ltda. - EADcon ${ }^{1}$ - para desenvolvimento de cursos de pósgraduação na modalidade de EAD. Pelo contrato firmado entre a EADcon e a Unitins, a EADcon participaria fornecendo conhecimento técnico e equipamentos, enquanto a Unitins se incumbiria da elaboração do projeto educacional e pedagógico, bem como pelas demais atividades da vida acadêmica (Brasil, 2008).

Uma brecha no artigo 21 da lei estadual 1160/00 permitiu à Unitins voltar a cobrar mensalidades dos interessados na formação dada pelo convênio EADcon/Unitins - o referido artigo só garantia a gratuidade dos cursos já em funcionamento à época, mas não aos que porventura fossem posteriormente criados. Mais do que isso: as mensalidades eram descontadas diretamente do salário, no caso de o aluno ser professor da rede estadual, já que havia um convênio entre a Secretaria de Educação do Estado e a Unitins (Araújo, 2008). O decreto estadual n. 1.672, de 27 de dezembro de 2002, confirmou a decisão, determinando que o que havia sobrado da Unitins se constituísse, novamente, em universidade paga, no artigo 4ํ. A instrução também pode ser lida no Estatuto

\footnotetext{
1 Segundo Pinto (2007), a empresa era conhecida, inicialmente, pela sigla Educon, passando a se chamar EADcon quando da aquisição de parte das cotas da empresa, em 2007, pela Universidade Estácio de Sá.
} 
Constitutivo da Unitins, artigo $4^{\circ}$, parágrafo $2^{\circ}$ : "os cursos serão oferecidos pela Unitins mediante contrapartida remuneratória" (Fundação, 2004).

A EADcon/Unitins ofereceu, inicialmente, o curso Normal Superior em salas instaladas em 64 dos 139 municípios do Estado (Moreira, 2009), número que chegou a 118 com o curso de Pedagogia, implantado posteriormente, sendo a primeira instituição de ensino superior brasileira a atuar com esta metodologia (Pinto, 2007). Em 2004, a portaria MEC 2145, de 16 de julho, credenciou nacionalmente a Unitins para oferta de cursos de graduação a distância, com a autorização do Curso Normal Superior.

Portanto, foi a partir de 2004 que a EADcon/Unitins passou a atuar em todo o território nacional, submetendo-se, assim, à regulação federal e não mais apenas à regulação estadual. A EADcon/Unitins chegou a oferecer cursos em todas as unidades da federação, com mais de 250 polos regionais (Moreira, 2009), e com diversos cursos de graduação, como Administração, Pedagogia, Letras, Matemática, Serviço Social, Ciências Contábeis, Análise de Sistemas, entre outros (Almeida, 2009). O número de alunos passou de 6.715 em fins de 2004 para 21.271 em 2005, 46.773 alunos em 2006, e chegou a 101.834 alunos em 2007 (Maia, 2009).

No entanto, a Unitins oferecia os seus cursos de maneira peculiar: os polos de apoio presencial se desdobravam em centros associados, ou seja, outras salas de aula também conectadas ao satélite de transmissão televisiva (Moreira, 2009), mas sem a estrutura mínima de um polo e, portanto, sem registro no MEC. Tratava-se de uma espécie de franquia da EADcon, já que, segundo Silva (2009), tais salas de aula não pertenciam à EADcon. A fiscalização do MEC entendeu que isto se tratava "de mais uma tentativa de burla à legislação educacional, que gera prejuízos imensuráveis aos estudantes, visto que [...] esses centros [...] não apresentam praticamente nada do que é exigido em termos de infraestrutura necessária" (Conselho, 2009, p.33). Ou seja, a EADcon/Unitins ignorou o decreto federal n. 6.303, que veda a existência de tais centros associados.

A EADcon/Unitins chegou a ter mais de 1600 salas de aula recebendo o seu sinal em todo o país, o que levava o número de alunos por tutor a variar entre 2500 e 12000 , dependendo do curso e da disciplina (Moreira, 2009). Araújo (2008) afirma que a EADcon/Unitins reunia as características menos desejáveis da educação a distância de qualidade, como interação em tempos homogêneos (e não flexíveis); comunicação em tempo diferente ou off-line, e não simultaneamente ou online, avaliações de múltipla escolha e a distância, e não expositivas e presenciais, cursos para muitos alunos; pouca interação; educação centrada no professor, e não no aluno, uso de teleconferência, e não de videoconferência.

Moreira (2009) aponta que todos os professores e tutores da Unitins eram contratados, tendo, portanto, o trabalho regido pela Consolidação das Leis do Trabalho e não pelo regime único dos servidores estaduais. Isto incentivava os professores a buscar estabilidade na crescente universidade federal. Pinto (2007) também afirma que, à época, as teleaulas não eram mais geradas a partir da sede da Unitins, mas da sede da EADcon, localizada em outro prédio de Palmas. Por fim, uma paralisação dos servidores no início de 2009 levou à revelação, por parte da Unitins, de que a folha de pagamento de seus funcionários era de responsabilidade exclusiva da EADcon (Coelho, 2009).

Tudo isto mostra que a Unitins, na prática, somente emprestava à EADcon o seu nome, o seu registro e a facilidade de, por ser uma universidade estadual, ter liberdade de 
criação de cursos e ser regulada e fiscalizada pelo próprio governo do Estado do Tocantins. Até mesmo os contratos dos alunos se faziam com a EADcon, o que, na visão do Ministério da Educação, era um procedimento ilegal, tendo em vista que os mesmos eram alunos da Unitins, uma universidade estadual, e o inciso IV do artigo 206 da Constituição Federal garante a gratuidade do ensino público em estabelecimentos oficiais (Conselho, 2009).

Por conta destes fatos, do aumento do rigor na fiscalização da EAD brasileira, especialmente nas universidades particulares, de denúncias realizadas ao MEC pelo Conselho Federal de Serviço Social - Cfess -, bem como pelos alunos do centro associado de Paranaiguara (GO), a partir de outubro de 2008, uma batalha jurídica e administrativa se estabeleceu entre a Unitins e a Seed-MEC. A Seed passou a investigar formalmente a Unitins com base nos Referenciais de Qualidade para Educação Superior a Distância (Brasil, 2007). O referido documento reconhece, na introdução, que não tem força de lei, mas que "será um referencial norteador para subsidiar atos legais do poder público no que se referem aos processos específicos de regulação, supervisão e avaliação da modalidade citada", o que, de fato, ocorreu neste caso.

Em diligências às cidades de Brasília, centro associado de Taguatinga, Juína (MT), Picos (PI), Santa Terezinha de Goiás e Sombrio (SC) (Maia, 2009), a Seed viu muitas outras irregularidades na instituição de ensino, como a falta de contato entre professores e alunos, assim como a falta de contato entre a Unitins e os polos e "centros associados", e acabou por expedir a nota técnica de supervisão 37/2008. Uma das descobertas mais extravagantes foi a de que a parceria entre EADcon e Unitins se dava com a Unitins como contratada e a EADcon como contratante, ou seja, com a empresa privada colocando a entidade pública a seu serviço, como conclui o parecer CNE/CES 299/2009 (Conselho, 2009).

A Seed conseguiu duas vitórias importantes entre o fim de 2008 e o início de 2009: primeiro, obteve o fechamento de cerca de 1000 centros associados da Unitins (Cieglinski, 2008); depois, por meio de despacho publicado no Diário Oficial da União de 26 de fevereiro de 2009, seção 1, p. 14, conseguiu impedir cautelarmente a realização de novos vestibulares para a EAD da Unitins, por sugestão do Ministério Público Federal no Estado do Tocantins (Brasil, 2009).

Pressionada a eliminar cobranças de mensalidades, a Unitins passou a alegar que não poderia conceder gratuidade a todos os alunos, uma vez que não seria obrigação do governo do Tocantins o subsídio à graduação superior de alunos de outros Estados. Assim, foi assinado, sob a supervisão do MPF-TO, um Termo de Ajuste de Conduta entre a Seed e a Unitins, no qual a instituição se comprometeu a transferir os alunos para outras instituições de ensino superior em situação regular (Giolo, 2010).

O TAC foi questionado, especialmente pelo fato de os alunos não desejarem a transferência compulsória, e acabou suspenso, duas semanas depois, graças a uma ação da EADcon que levou à concessão de liminar no sentido de anular os seus efeitos (Justiça, 2009). Sugeriu-se, então, à Unitins que assinasse um Termo de Saneamento de Deficiências (TSD), o que não foi feito. Assim, a Seed, por meio da portaria MEC 44, de 18 de agosto de 2009, descredenciou a Unitins para a oferta dos cursos EAD, garantindo, no entanto, o direito dos alunos matriculados de prosseguir estudando na Unitins e receber os seus diplomas, ainda que pagando mensalidades (Moreira, 2009). 
A Unitins e a EADcon começaram a se articular buscando reverter a decisão no Conselho Nacional de Educação: houve uma nova mudança na reitoria; em setembro de 2009, um novo contrato entre a EADcon e a Unitins foi assinado, passando a EADcon a constar como contratada, e não contratante, bem como a responsabilidade pelas aulas e materiais didáticos passariam a ser da Unitins, a única instituição autorizada a ofertar os cursos (Unitins, 2009). Tais esforços não evitaram o descredenciamento da Unitins, ratificado em decisão do Conselho Nacional de Educação em 7 de outubro de 2009 (Conselho, 2009).

Um movimento de reestruturação da instituição foi articulado. Tal movimento se beneficiou do fato de ter havido, à mesma época, a troca do governador ${ }^{2}$. O novo governador, que em dezembro de 2009 criou uma comissão para estudar caminhos para a reformulação da universidade (Lins, 2009c), foi favorável à transformação da Unitins em instituição com oferta de ensino presencial. A Unitins contou, também, com emendas parlamentares federais que buscaram destinar $R \$ 50$ milhões à reestruturação da instituição (Araújo, 2009). Desta forma, em julho de 2010 foi aberto vestibular para quatro cursos presenciais de graduação (Direito, Engenharia Agronômica, Serviço Social e Sistemas de Informação) (Fundação, 2010).

A Unitins também obteve, à mesma época, o seu recredenciamento para a oferta de cursos de graduação a distância, agora gratuitos, por meio do sistema Universidade Aberta do Brasil, conforme portaria MEC n. 837, de 24 de junho de 2010, com lançamento do primeiro edital de seleção de alunos para o curso de Pedagogia em 7 de dezembro de 2010 (Pereria, 2010).

\section{Considerações finais}

Nestas considerações finais, retomaremos, pela ordem, as questões de pesquisa estabelecidas na introdução, fazendo uma abordagem sistemática das conclusões que podem ser obtidas a partir da leitura do capítulo anterior, ou seja, de nossos resultados de pesquisa.

Em relação à questão um, percebemos que foram vários os fatores políticos que colocaram em risco a implantação da educação a distância de qualidade na Unitins. $O$ principal deles foi o fato de que a Unitins não era fornecedora de serviços educacionais para os estudantes de forma direta, mas sim uma contratada de uma empresa particular. A sobreposição da lógica de mercado aos interesses públicos fez com que se reduzissem índices de qualidade em educação a distância, como a razão entre o número de professores e alunos, a níveis intoleráveis por parte dos estudantes.

Pereira (2007) já tratava da gravidade das "implicações da junção de interesses públicos da Unitins com interesses privados" da EADcon, juntamente com a "necessidade de uma reflexão mais aprofundada sobre as consequências da inserção da gestão privada nos espaços públicos universitários, transformando a educação em 'prestação de

2 Os mandatos do governador Marcelo de Carvalho Miranda e do vice-governador Paulo Sidnei Antunes foram cassados pelo Tribunal Superior Eleitoral em 26 de junho de 2009. Em 8 de setembro do mesmo ano foram julgados improcedentes os recursos e Carlos Henrique Amorim, presidente da Assembléia Legislativa, assumiu provisoriamente o cargo de governador do Estado. Eleições indiretas foram convocadas e realizadas em 8 de outubro de 2009, dando a vitória ao deputado Gaguim (Lins, 2009a; 2009b). 
serviços"' (p. 85). A autora entendeu que tais interesses levaram à constituição de um projeto de formação que careceu de um aprofundamento teórico que entendesse a aprendizagem como processo cognitivo colaborativo, que permitisse ao aluno se reconhecer e se colocar "em uma posição de análise, de reflexão e crítica sobre o conhecimento e a realidade", e não como mero assimilador de conteúdos.

Há de se concordar com as conclusões de Pereira, e ainda acrescentar que as constantes mudanças de comando na Unitins também prejudicaram a qualidade dos cursos. Como discutimos ao longo do texto, sistemas de educação a distância demandam um tempo de maturação elevado para atingir índices de excelência. As constantes mudanças na reitoria, que documentos anteriormente citados atribuem aos interesses políticos do governo, provocavam mudanças de gestão que não são bem-vindas na $E A D$, uma vez que os alunos não participam tão ativamente, como nos cursos presenciais, de órgãos colegiados da instituição, tampouco buscam representatividade nos diretórios e centros acadêmicos, sendo, assim, mais difícil compreender, acompanhar e influenciar a dinâmica das mudanças. Além disso, a precarização dos contratos de trabalho com os professores levou a uma alta rotatividade de profissionais, o que, de forma similar, reduziu a qualidade e a estabilidade do sistema de educação a distância que se pretendia implantar.

Quanto à questão dois de pesquisa, pode-se afirmar que os agentes governamentais federais tiveram um papel crescentemente ativo na garantia da qualidade dos cursos da Unitins. Se, em 2004, autorizaram a Unitins a manter abertos cursos a distância por cinco anos, e só começaram um processo rigoroso de avaliação da Unitins a partir de uma denúncia de alunos da instituição, ao longo de 2008 e 2009 não mediram esforços para garantir uma solução adequada para os alunos, sem dúvida, o elo mais fraco da cadeia. A evolução, contudo, está relacionada a um aumento da experiência da Secretaria de Educação a Distância do MEC em relação aos atos de autorização e fiscalização em geral, no sentido de ser mais cautelosa e rigorosa, e não algo específico para o caso Unitins. As autorizações de abertura de cursos na modalidade a distância em prazo mais curto a partir de 2006 mostram que o MEC percebeu que a fiscalização da EAD deve ser mais rigorosa do que a educação presencial.

Em relação aos agentes estaduais, somente foi percebida uma mudança de postura de uma tentativa de garantir os lucros da empresa privada para uma ação que realmente renovasse a educação a distância da Unitins quando dos coincidentes eventos da substituição do governador e do descredenciamento da instituição junto ao MEC, em outubro de 2009. A solução, no entanto, não deixou de passar pelos entes federais, como deputados representantes do Estado do Tocantins, que conseguiram, por meio de emendas parlamentares, garantir verbas para a estruturação de uma educação a distância efetivamente pública e gratuita na Unitins.

Por fim, em resposta à questão de pesquisa de número três, nota-se que os interesses dos agentes públicos e privados no que tange à estruturação e gestão da EAD na Unitins interagiram de forma a priorizar aspectos financeiros em lugar dos aspectos pedagógicos. É extremamente representativo e marcante o fato de que, no convênio entre a EADcon e a Unitins, esta última, a entidade pública, constava como contratada, e não como contratante. Ou seja, a Unitins operava a serviço de uma empresa privada, a serviço do capital, e não a serviço dos alunos - estes firmavam contrato com a EADcon. 
Não surpreende, portanto, que a prioridade da Unitins não fosse o bom atendimento dos alunos: estes não tinham qualquer relação direta com a universidade; todas as relações eram mediadas pela EADcon.

Note-se que a Unitins, como universidade estadual de uma unidade da federação periférica, de reduzida população e peso econômico, sendo a última unidade da federação a ter a sua própria universidade federal, antes de buscar atender a alunos de todo o país, deveria ter garantido o atendimento eficiente dos alunos do próprio Tocantins. Com isto, percebe-se que os interesses privados sobrepujaram os reais interesses públicos, especialmente o de garantir educação superior pública gratuita e de qualidade, com a garantia da gestão democrática, como prevê a Constituição Federal de 1988.

Esperamos, com os dados construídos, que o conhecimento do caso Unitins possa servir de lição à boa gestão pública educacional, especialmente na difícil missão de interiorização do ensino superior. Ainda que o contexto deste caso tenha sido o de um Estado da região Norte, certamente as conclusões podem ser estendidas para qualquer outro caso do Brasil. Não pretendemos esgotar o tema, mas é certo que conseguimos trazer à tona questões que pouco têm sido discutidas no meio acadêmico, em livros, periódicos e congressos da área.

\section{Referências}

ALMEIDA, Mariana Carla de. Estudo da usabilidade da interface do ambiente virtual de aprendizagem da Unitins. Brasília: UNB, 2009. 224f. Dissertação (mestrado em Educação). Faculdade de Educação, Universidade de Brasília.

ALONSO, Kátia Morosov. A expansão do ensino superior no Brasil e a EAD: dinâmicas e lugares. Educação \& Sociedade, Campinas, v. 31, n. 113, 2010, p. 1319-1335.

ARAÚJO, Ana Mariana. Unitins contará com emenda de $\mathrm{R} \$ 50$ milhões para projeto de reestruturação. Fundação Universidade do Tocantins. 2009. Disponível em: <http:// www. unitins.br/portal/Noticia_principal_Visualizar.aspx?in=1809>. Acesso em: 17 maio 2011.

ARAÚJO, Nataniel da Vera-Cruz Gonçalves. O normal superior telepresencial e a trilogia: política educacional, formação de professores e educação a distância. São Luís: UFMA, 2008. 136f. Dissertação (mestrado em Educação). Universidade Federal do Maranhão.

BARRETO, Raquel Goulart. Tecnologia e educação: trabalho e formação docente. Educação \& Sociedade, Campinas, v. 25, n. 89, 2004, p. 1181-1201.

BATES, Anthony (Tony) W. Distance education in dual mode higher education institutions: challenges and changes. E-Learning and distance education resources. The University of British Columbia, 2000. Disponível em: <http://bates.cstudies.ubc.ca/papers/ challengesandchanges.html>. Acesso em: 28 jul., 2010.

BRASIL. Justiça Federal de $1^{\text {a }}$ Instância. Seção Judiciária do Estado do Tocantins. Primeira Vara. Decisão Interlocutória. Cautelar Inominada. Demandante: Sociedade Civil de Educação Continuada Ltda. Demandado: União, Fundação Universidade Federal do Tocantins e Ministério Público Federal. 2008. Disponível em: <http:// www. ogirassol. com. $\mathrm{br} /$ pagina. php? idnoticia $=6253>$. Acesso em: 10 maio 2011.

BRASIL. Ministério da Educação. Perguntas \& respostas TAC Unitins. Brasília, DF: Ministério da Educação, 2009. Disponível em: <http:// ava2.unitins.br/ava/Arquivos/ faq_tac.pdf>. Acesso em: 15 maio 2011. 
BRASIL. Ministério da Educação. Secretaria de Educação a Distância. Referenciais de qualidade para educação superior a distância. 2007. Disponível em: <http:// portal.mec. gov. br/seed/arquivos/pdf/legislacao/refEAD1.pdf>. Acesso em: 10 maio 2011.

CIEGLINSKI, Amanda. Cursos a distância fechados pelo Ministério da Educação. Agência Brasil. Gazeta Digital. 2008. Disponível em: <http:// www.gazetadigital.com.br/conteudo/ show/secao/4/materia/195266>. Acesso em: 17 set., 2011.

COELHO, Umberto Salvador. Humberto Falcão renuncia, Unitins tem nova reitora. Conexão Tocantins. 2009. Disponível em: <http://conexaoto.com.br/2009/02/10/humbertofalcao-renuncia-unitins-tem-nova-reitora>. Acesso em: 17 set., 2011.

CONSELHO NACIONAL DE EDUCAÇÃO. Recurso contra decisões do Secretário de Educação a Distância que determinaram medidas cautelares relativas à oferta de cursos superiores na modalidade à distância pela Universidade do Tocantins e o descredenciamento da Instituição para esta modalidade. 2009. Disponível em: $<$ http://portal.mec.gov.br/index.php?option=com_docman\&task=doc_download\&gid=1617 \& Itemid=>. Acesso em: 10 maio 2011.

DOURADO, Luiz Fernandes. Políticas e gestão da educação superior a distância: novos marcos regulatórios? Educação \& Sociedade, Campinas, v. 29, n. 104, 2008, p. 891-917.

ELIASQUEVICI, Marianne Kogut; PRADO JR., Arnaldo Corrêa. O papel da incerteza no planejamento de sistemas de educação a distância. Educação e Pesquisa, v. 34, n. 2, 2008, p.309-325.

FREITAS, Dirce Nei Teixeira de. A gestão educacional na interseção das políticas federal e municipal. Revista da Faculdade de Educação, São Paulo, v. 24, n. 2, 1998, p.29-50.

FUNDAÇÃO UNIVERSIDADE DO TOCANTINS. Estatuto Constitutivo. Palmas, TO: Unitins, 2004. Disponível em: <http://www.unitins.br/portal/legislacao/Estatuto\%20 UNITINS.pdf>. Acesso em: 17 maio 2011.

FUNDAÇÃO UNIVERSIDADE DO TOCANTINS. Assessoria de Comunicação. Inscrições para vestibular presencial da Unitins seguem até sexta, 18. 2010. Disponível em: <http://secom.to.gov.br/noticia/2010/6/14/inscricoes-para-vestibular-presencial-da-unitinsseguem-ate-sexta-18>. Acesso em: 17 maio 2011.

GIOLO, Jaime. A educação a distância e a formação de professores. Educação \& Sociedade, Campinas, v. 29, n. 105, 2008, p. 1211-1234.

GIOLO, Jaime. Educação a distância: tensões entre o público e o privado. Educação \& Sociedade, Campinas, v. 31, n. 113,2010, p. 1271-1298.

GOUVÊA, Guaracira; OLIVEIRA, Carmen Irene. Educação a distância na formação de professores. Rio de Janeiro: Vieira\&Lent, 2006.

JUSTIÇA Federal suspende efeitos do TAC sobre Unitins e Educom. Conexão Tocantins. 2009. Disponível em: <http://conexaoto.com.br/ 2009/05/11/justica-federal-suspendeefeitos-do-tac-sobre-unitins-e-educom>. Acesso em: 17 set., 2011.

KIPNIS, Bernardo. Educação superior a distância no Brasil: tendências e perspectivas. In: LITTO, Frederic; FORMIGA, Marcos (org.). Educação a distância: o estado da arte. São Paulo: Pearson, 2009, p. 209-214.

LINS, Aquiles. TSE julga embargos e Marcelo Miranda deixa governo. Secretaria da Comunicação Social. Governo do Estado do Tocantins. 2009a. Disponível em: <http:// secom.to.gov.br/noticia/2009/9/9/tse-julga-embargos-e-marcelo-miranda-deixa-governo/>. Acesso em: 17 maio 2011. 
LINS, Aquiles. Carlos Henrique Gaguim é eleito governador do Tocantins. Secretaria da Comunicação Social. Governo do Estado do Tocantins. 2009b. Disponível em: <http://secom.to.gov.br/noticia/2009/10/9/carlos-henrique-gaguim-e-eleito-governador-dotocantins/>. Acesso em: 17 maio 2011.

LINS, Aquiles. Governador cria comissão multilateral para reestruturação da Unitins. Casa Civil. Governo do Estado do Tocantins. 2009c. Disponível em: <http://casacivil.to.gov.br/ noticias. php?id=458>. Acesso em: 17 maio 2011.

MAIA, Maria Zoreide Britto. Razões para um descredenciamento em EAD: o caso Unitins. In: COLÓQUIO INTERNACIONAL SOBRE GESTÃO UNIVERSITARIÁ NA AMÉRICA DO SUL, 9, 2009, Florianópolis. Anais... Florianópolis: UFSC, 2009. Disponível em: <http://www.inpeau.ufsc.br/wp/wp-content/BD_documentos/coloquio9/IX-1066.pdf>. Acesso em: 17 maio 2011.

MORAES, Reginaldo Carmello Corrêa de. Educação a distância e ensino superior: introdução didática a um tema polêmico. São Paulo: Senac, 2010.

MOREIRA, Alcides do Nascimento. Percepção docente e discente do modelo pedagógico de EAD: mídia televisiva e ambiente virtual de aprendizagem: o caso da Unitins. Brasília: UNB, 2009. 156f. Dissertação (mestrado em Educação). Faculdade de Educação, Universidade de Brasília.

MORETZ-SOHN, Maria Cristina D'Almeida. A estruturação do ensino superior no Tocantins: caminhos e descaminhos da Unitins. Goiânia: UFG, 2002. 143f. Dissertação (mestrado em Educação). Faculdade de Educação, Universidade Federal de Goiás.

PEREIRA, Isabel Cristina Auler. Apreensões e apropriações do tempo e espaço na educação a distância da Unitins. Salvador: UFBA, 2007. 242f. Tese (doutorado em Educação). Faculdade de Educação, Universidade Federal da Bahia.

PERERIA, Jodevaldo. Ciência e Tecnologia participa de lançamento do Processo seletivo UAB/Unitins. Secretaria da Ciência e Tecnologia. Governo do Estado do Tocantins. 2010. Disponível em: <http://www.tecnologia.to.gov.br/noticia.php?noticia=110>. Acesso em: 17 maio 2011.

PINTO, Simone Andréa. A presença da ausência: a formação do pedagogo na modalidade a distância da Universidade do Tocantins. Brasília: UNB, 2007. $233 f$. Dissertação (mestrado em Educação). Faculdade de Educação, Universidade de Brasília.

PRETI, Oreste. Educação a distância e globalização: desafios e tendências. Revista Brasileira de Estudos Pedagógicos, Brasília, v. 79, n. 191, 1998, p. 19-30.

PRETTO, Nelson de Luca; PEREIRA, Isabel Cristina Auler. Ensino superior no Brasil: a implantação da Unitins e o uso da EAD como estratégia expansionista de uma universidade pública. Perspectiva, v. 26, n. 2, 2008, p. 663-691.

SILVA, Angela Noleto da. A formação por um fio: o tutor na EAD no estado do Tocantins. Goiânia: UFG, 2009. 150f. Dissertação (mestrado em Educação). Faculdade de Educação, Universidade Federal de Goiás.

SILVA JR., João dos Reis. Reformas do estado e da educação e as políticas públicas para a formação de professores a distância: implicações políticas e teóricas. Revista Brasileira de Educação, n. 24, 2003, p. 78-94.

SOUZA, Raquel Aparecida. Da Unitins à UFT: modelos e práticas gestoriais na educação superior do Estado do Tocantins no limiar do século 21. Uberlândia: UFU, 2007. 178 f. Dissertação (mestrado em Educação). Faculdade de Educação, Universidade Federal de Uberlândia. 
TOCANTINS. Lei n. 872, de 13 de novembro de 1996. Determina o processo de extinção da autarquia em que se constitui a Universidade do Tocantins. Diário Oficial do Estado, Palmas, n. 562, 1996.

TOCANTINS. Lei n. 1160, de 19 de junho de 2000. Reestrutura a Fundação Universidade do Tocantins e adota outras providências. Diário Oficial do Estado, Palmas, n. 937, 2000.

TOCANTINS. Decreto n. 1672, de 27 de dezembro de 2002. Dispõe sobre a Fundação Universidade do Tocantins - Unitins. Diário Oficial do Estado, Palmas, n. 1347, 2002.

UNITINS fecha acordo com a empresa parceira. Conexão Tocantins. 2009. Disponível em: <http://conexaoto.com.br/2009/09/15/unitins-fecha-acordo-com-a-empresa-parceira>. Acesso em: 17 set., 2011.

Daniel Perdigão Nass é professor na Universidade Federal do Tocantins, doutor em Ensino de Ciências e especialista em Gestão Educacional.

Endereço: Caixa postal 66 - 77402-970 - Gurupi - TO - Brasil.

E-mail:perdigao@uft.edu.br.

Recebido em 10 de setembro de 2013.

Aceito em 29 de setembro de 2013. 